\title{
O PROUNI NA ENCRUZILHADA: ENTRE A CIDADANIA E A PRIVATIZAÇÃO
}

\author{
PROUNI AT A CROSSROAD: BETWEEN \\ CITIZENSHIP AND PRIVATIZATION
}

PROUNI AU CROISEMENT : ENTRE

LA CITOYENNETÉ ET LA PRIVATISATION

EL PROUNI EN LA ENCRUCIJADA: ENTRE LA CIDADANIA Y LA PRIVATIZACIÓN

\author{
Afrânio Mendes Catani * \\ Renato de Sousa Porto Gilioli **
}

"Espero que o Prouni não seja uma mentira como a Lei Áurea". Solange Aparecida F. de Campos, estudante da ONG Educafro e beneficiária selecionada pelo Prouni (FSP, 2005).

\section{RESUMO}

O objetivo do artigo é discutir a relação entre governo e associaçôes das mantenedoras de ensino superior no processo de elaboração, modificação e aprovação do Programa Universidade para Todos (Prouni), que integra a Reforma Universitária do governo Lula. As alteraçôes incorporadas representaram, sobretudo, concessōes ao lobby das instituiçōes de ensino superior do setor privado, que obteve quase todas as suas reivindicaçôes. Nesse contexto, o Prouni pode ser caracterizado como voltado a promover o acesso - e não a permanência - de estudantes de baixa renda ao nivel superior. O Programa oferece uma cidadania de segunda classe aos bolsistas, abandona-os à iniciativa privada, amplia o poder das IES do setor e as salva do crônico problema da evasão de alunos.

Palavras-chave: Educação superior. Acesso. Permanência. Prouni.

* Doutor em Sociologia pela Universidade de São Paulo (USP, 1992). Professor da Faculdade de Educação (FE) e Programa de Pós-Graduação em Integração da América Latina (PROLAM) da USP. Pesquisador do CNPq (amcatani@usp.br).

** Mestre e doutorando na FE-USP e historiador (resopogi@uol.com.br). 
Dentre as discussões e propostas que envolvem a Reforma Universitária do governo Lula, destaca-se o Programa Universidade Para Todos (Prouni). Desde o anúncio oficial de que o Projeto de Lei seria encaminhado ao Parlamento (13.05.2004) até a versão definitiva da Lei 11.096 (13.01.2005), o Programa foi alterado diversas vezes, geralmente atendendo às reivindicaçôes das Instituições de Ensino Superior (IES) particulares e beneficentes.

Pretendemos levantar, aqui, os principais aspectos relacionados à dinâmica das mudanças sofridas pelo projeto até o início de 2005, enfocando as relações entre governo e entidades representantes das mantenedoras de ensino superior. Em essência, o Prouni promove uma política pública de acesso - mas não de permanência - ao ensino superior, além de orientar-se pela concepção de assistência social, oferecendo benefícios e não propriamente direitos aos egressos do ensino médio público. Ademais, os cursos superiores ofertados nas IES privadas e filantrópicas são, muitas vezes, de qualidade questionável e voltados apenas às demandas imediatas do mercado.

A Reforma Universitária do governo Lula compreende, além do Prouni: cotas para alunos da rede pública (com "sub-cotas" para negros e indígenas) em universidades públicas federais; obrigatoriedade do Exame Nacional do Ensino Médio (Enem) para os seus concluintes; ampliação das universidades federais; criação de loteria federal para financiar a educação superior - destinada ao levantamento de recursos para o Fies (Financiamento ao Estudante do Ensino Superior) e as bolsas-permanência para estudantes de baixa renda no ensino superior.

Deise Mancebo destaca que "...um dos primeiros passos da Reforma Universitária seria a edição de medidas que, a um só tempo, suprissem a necessidade de ampliação da rede de ensino superior e não implicassem gastos para a União" (MANCEBO, 2004, p. 80). O Prouni insere-se nesse quadro, promovendo o acesso à educação superior com baixo custo para o governo. Seu objetivo é cumprir a meta do Plano Nacional de Educação (PNE - Lei 10.172/2001) de aumentar a proporção de jovens na faixa de 18 a 24 anos que freqüentam curso superior para a casa de 30\% até 2010 (a cifra atual encontra-se em torno dos $9 \%$, apesar da expansão das matrículas no setor privado na última década). Pretende, também, responder ao aumento da demanda por acesso à educação superior, derivada do crescente número de jovens que conclui o ensino médio. Para tanto, vale-se da alta ociosidade do ensino superior privado ( $35 \%$ da vagas em 2002 e 42\% em 2003, segundo o Censo do Inep).

Desde o princípio, o MEC queria instituir o Prouni através de medida provisória. No entanto, a decisão do governo foi encaminhar Projeto de Lei (PL) ao Congresso em maio. Assim, salientaremos seus principais aspectos para verificar as mudanças ocorridas nas medidas legais subseqüentes.

Inicialmente, o PL previa apenas bolsas de estudo integrais concedidas a "brasileiros não portadores de diploma de curso superior e cuja renda familiar não exceda a um salário mínimo per capita" (BRASIL, MEC, 2004, art. $1^{\circ}, \$ 1^{\circ}$ ). Destinadas a concluintes do ensino médio em escolas públicas e a professores ${ }^{1}$ da rede pública, o MEC projetava que as bolsas integrais poderiam atender de 70 a 80 mil beneficiários em 2005. A estimativa era preencher de 280 a 320 mil vagas em quatro ou cinco anos. 
Os critérios escolhidos para selecionar os beneficiários foram a nota e o perfil socioeconômico do estudante no Enem (exceto para professores da rede pública). Os alunos ingressantes no ensino superior através do Prouni seriam, assim, dispensados "do processo seletivo específico das instituições privadas" (idem, art $3^{\circ}$, parágrafo único), por exemplo, o vestibular.

As IES não beneficentes (com ou sem fins lucrativos) ofereceriam "uma bolsa para cada nove alunos regularmente matriculados em cursos efetivamente instalados" (idem, art. $5^{\circ}$, caput). A expressão "alunos regularmente matriculados" não aparece acompanhada de "pagantes", termo incluído na Medida Provisória (MP) e na Lei do Prouni. Já as IES beneficentes deveriam destinar uma bolsa integral "para cada quatro alunos de cursos de graduação ou seqüencial de formação específica" (idem, art. 11).

Um dos elementos que deu destaque ao Prouni foi a inclusão de políticas afirmativas, através da destinação de percentuais das bolsas oferecidas aos autodeclarados negros e indígenas (nas proporçôes do censo populacional do IBGE para cada Estado e para o Distrito Federal).

No PL, o vínculo das IES ao Prouni se daria por "termo de adesão" a ser assinado com o MEC, vigente por 10 anos e renovável por iguais períodos. Ficaria vedada a participação no Programa de instituições com desempenho insuficiente no Sistema Nacional de Avaliação de Educação Superior (Sinaes), "por dois anos consecutivos ou três intercalados, no período de cinco anos" (art. $7^{\circ}, \$ 4^{\circ}$ ). Esse dispositivo foi alterado na MP e na Lei: cedendo às pressões das mantenedoras, o governo adotou regra menos rígida e o desvinculamento passou a depender do desempenho insuficiente da IES no Sinaes por três anos consecutivos.

A adesão das instituições ao Prouni proporciona isenção do Imposto de Renda das Pessoas Jurídicas (IRPJ), da Contribuição Social sobre o Lucro Líquido (CSLL), da Contribuição Social para Financiamento da Seguridade Social (Cofins) e da Contribuição para o Programa de Integração Social (PIS). Em dezembro de 2004, a previsão do MEC era de que a renúncia fiscal seria da ordem de $\mathrm{R} \$ 196$ milhões anuais (COLLUCCI, 2004).

O PL criou um condicionante: as IES não poderiam se credenciar ao Fies caso não aderissem ao Prouni. O dispositivo causou tanto incômodo entre os representantes das mantenedoras, que foi alterado já na MP, que suavizou essa restrição: "terão prioridade na distribuição dos recursos disponíveis no Fies as instituiçōes que aderirem ao Prouni” (BRASIL, PODER EXECUTIVO, 2004, art. 13).

Para as instituições que aderissem ao Prouni e descumprissem as regras legais, o PL previa: multa de até $1 \%$ do faturamento anual (depois retirada da MP e da Lei); acréscimo de bolsas, caso a porcentagem de $10 \%$ e $20 \%$ de bolsas integrais (respectivamente para IES não-beneficentes e beneficentes) ficasse abaixo do mínimo; desvinculação do Prouni (em caso de reincidência). 


\section{O LOBBY DAS MANTENEDORAS}

Tão logo o PL chegou ao Congresso, as associaçôes das mantenedoras apresentaram contrapropostas com o objetivo de modificar o Prouni. Tendo à frente principalmente a Associação Nacional das Universidades Particulares (Anup), a Associação Brasileira de Mantenedoras de Ensino Superior (Abmes) e o Sindicato das Entidades Mantenedoras de Estabelecimentos de Ensino Superior no Estado de São Paulo (Semesp), a maioria das reivindicações do setor foi atendida através de emendas apresentadas por deputados.

Além da alteração sugerida de desobrigar as filantrópicas de destinar $20 \%$ da gratuidade em bolsas integrais, as mantenedoras queriam incluir bolsas parciais, ampliar a faixa de renda familiar per capita de um para três salários mínimos e exigir processos seletivos internos das instituições - e não só pelo Enem. Já as IES com fins lucrativos queriam reservar apenas $5 \%$ de suas vagas aos alunos carentes, não oferecer bolsas integrais e conceder bolsas parciais de $20 \%$ a $80 \%$ (OESP, 2004). A reivindicação de bolsas parciais de $50 \%$ foi apresentada pelo vice-presidente do Semesp e logo aceita pelo relator da comissão que analisou o PL, deputado Irineu Colombo (PT-PR).

Diante de tais propostas, o Prouni começava a ser desfigurado. Na melhor das hipóteses, constituiu-se em programa assistencialista, que prioriza o acesso - e não a permanência - do estudante ao ensino superior. Aliás, até os próprios representantes das mantenedoras levantaram a questão da permanência: "Um dos pontos criticados por representantes das instituições e dos estudantes é a renda per capita exigida, de um salário mínimo, o que impossibilitaria o estudante de se manter na universidade" (TAKAHASHI, 2004). Contudo, a advertência tinha destino certo, pois as bolsas parciais para estudantes de renda muito baixa não resolveriam o problema crônico da evasão escolar (e, portanto, da receita auferida com as mensalidades) nas IES privadas. Daí a sugestão de ampliar a renda familiar per capita para 3 salários mínimos.

A essas reivindicações somaram-se mais duas apresentadas pelo Semesp (ambas atendidas desde a MP): participação, no Programa, de estudantes que tinham cursado o ensino médio privado na condição de bolsistas integrais e inclusão de uma regra de transição tributária para as IES "sem fins" se transformarem em "com fins" lucrativos. Havia, também, a pressão das universidades filantrópicas contra a conversão dos $20 \%$ de gratuidade exclusivamente em bolsas integrais.

O PL recebeu 292 propostas de emenda que “...mostram, em sua maioria, grande influência das instituiçōes privadas e filantrópicas de ensino superior" (PARAGUASSÚ, 2004). Dentre as aceitas, abriu-se a possibilidade de as IES filantrópicas destinarem meia-bolsa ( $50 \%$ do valor do curso) aos beneficiários, diferentemente do previsto no PL. Da mesma forma, a exigência de bolsas integrais nas beneficentes caiu de $20 \%$ para $10 \%$. Por sua vez, a faixa de rendimento dos bolsistas integrais subiu de um para um e meio salário mínimo. Isso tudo já fora aceito pelo relator do PL na Câmara até o dia 12.08.2004.

As propostas de mudança no PL ainda pressionavam para permitir que os funcionários (e seus dependentes) bolsistas das IES pudessem ser contabilizados como beneficiários do Prouni. Outras alterações foram ainda reivindicadas pelo Semesp, dentre as quais "dar mais clareza ao conceito de bolsa de estudo parcial e integral e incluir 
a bolsa parcial de um terço; a prestação de serviços comunitários para os alunos beneficiados" (FOLHA ONLINE, 2004a).

Em 25.08.2004, a votação na Câmara já havia sido adiada pela segunda vez. Acuado, mas ainda tentando demonstrar força, o governo anunciara no dia anterior que mais de 30 IES privadas já teriam aderido ao Prouni. O efeito foi inverso, provocando rejeição geral ao relatório apresentado pelo deputado Colombo. Diante da falta de acordo político, o governo passou a negociar diretamente com as mantenedoras até obter aprovação majoritária do setor. Com isso, editou a Medida Provisória (MP) do Prouni.

\section{A MP DO PROUNI}

Instituído por meio da MP n. 213, publicada em 13.09.2004, o Prouni adotou a maioria das reinvidicações das IES. O texto da MP trouxe, já no caput de seu artigo $1^{\circ}$, a "concessão de bolsas de estudo integrais e bolsas de estudo parciais de cinqüenta por cento (meia-bolsa)" (BRASIL, PODER EXECUTIVO, 2004). Ainda não fora atendida a reivindicação de bolsas parciais menores (as mantenedoras sugeriam porcentagens de um terço ou até mesmo de $20 \%$ ), mas a instituição da meia-bolsa já representava vitória significativa do setor.

Quanto à bolsa integral, adotou-se a ampliação da renda limite de um para um e meio salário mínimo familiar per capita - $\mathrm{R} \$ 390,00$. Ao mesmo tempo, para a bolsa parcial foi criado um novo limite: 3 salários mínimos - $\mathrm{R} \$ 780,00$. As bolsas parciais devem considerar "todos os descontos regulares oferecidos pela instituição, inclusive aqueles dados em virtude do pagamento pontual das mensalidades" (art. $1^{\circ}, \S 4^{\circ}$ ), ponto destacado positivamente pela assessoria jurídica do Semesp em seminário de orientação às mantenedoras referente ao Prouni (SEMESP, 2004).

Foram acrescentados à MP os estudantes com necessidades especiais como destinatários das bolsas e, também, conforme demanda do Semesp, quem cursou todo o ensino médio na condição de bolsista integral em instituiçōes privadas. $\mathrm{O}$ art. $3^{\circ}$ trouxe a novidade de uma "seleção" a ser realizada pela IES após a "pré-seleção" do Enem, atendendo às mantenedoras.

Concretizando outra sugestão do Semesp, o parágrafo único do art. $4^{\circ}$ da MP dispunha: "O estudante beneficiário do Prouni poderá prestar serviços comunitários, nos termos de normas expedidas pelo MEC, aplicando-se à atividade o disposto na Lei 9.608, de 18 de fevereiro de 1998". Portanto, mesmo sendo membros de família de baixa renda, os estudantes ficaram sujeitos a se tornar mão-de-obra gratuita para as IES, pois a Lei 9.608/98 dispõe sobre o serviço voluntário.

Pela MP, as IES não beneficentes (com ou sem fins lucrativos) deveriam oferecer uma bolsa integral "para cada nove estudantes pagantes regularmente matriculados em cursos efetivamente nela instalados" (art. 50, caput). Diferentemente do PL, aqui se insere o termo "pagantes" ${ }^{2}$ (fazendo a proporção de beneficiários incidir sobre a receita das mensalidades). No entanto, metade dos $10 \%$ de bolsas integrais das IES não beneficentes poderia ser convertida em bolsas parciais de $50 \%$, reduzindo o parco caráter cidadão do Programa. 
A limitação das bolsas parciais de 50\% reside no fato de que, caso seus beneficiários não paguem em dia a parte que lhes cabe, não terão direito de renovar matrícula no semestre ou ano seguinte do curso, conforme estabelece o art. $5^{\circ}$ da Lei 9.870/99: "os alunos já matriculados, salvo quando inadimplentes, terão direito à renovação das matrículas" (BRASIL, PRESIDENCIA DA REPÚBLICA, 1999). ${ }^{3}$ A possibilidade de evasão durante o curso, nesses casos, aumenta bastante. Assim, ressaltamos que o Prouni institui uma política de acesso, mas não de permanência na educação superior, na qual o estudante será tratado como consumidor, e não como cidadão.

Conforme a MP determina, o termo de adesão ao Prouni deve conter as seguintes cláusulas: proporção de bolsas oferecidas por curso, turno e unidade; percentual de bolsas destinado prioritariamente às cotas para negros e indígenas. Caso desrespeitadas, as penas que o MEC pode aplicar são o restabelecimento das proporções acordadas no termo de adesão e, em caso de reincidência, a suspensão das isenções tributárias concedidas pelo Prouni. No entanto, a multa prevista no PL foi retirada.

Por sua vez, as IES beneficentes ganharam com a edição da MP, pois a obrigatoriedade de bolsas integrais nessas instituições foi reduzida de $20 \%$ (conforme redação do PL) para $10 \%$ da receita bruta, menor do que o percentual de bolsas integrais que algumas PUCs, por exemplo, já ofereciam a seus alunos antes do Prouni. Os 10\% restantes da gratuidade deveriam ser destinados a "bolsas parciais de cinqüenta por cento e a assistência social em programas extracurriculares" (art. $9^{\circ}, \$ 2^{\circ}$ ). Tal dispositivo era reivindicação do setor, que não queria usar toda a gratuidade apenas em bolsas integrais, mantendo assim suas pouco fiscalizadas ações beneficentes.

Outro ponto polêmico foi o art. 12, segundo o qual as IES sem fins lucrativos receberão privilégios para se tornar entidades com fins lucrativos: "passarão a pagar a quota patronal para a previdência social de forma gradual, durante o prazo de cinco anos, na razão de vinte por cento do valor devido a cada ano, cumulativamente, até atingir o valor integral das contribuições devidas" (BRASIL, PODER EXECUTIVO, 2004).

A transformação de natureza jurídica de uma entidade sem fins lucrativos fere, para alguns, o art. 213 da Constituição Federal de 1988 (CF 88), segundo o qual uma escola comunitária, confessional ou filantrópica só pode receber recursos públicos se, em caso de encerramento de suas atividades, destinar seu patrimônio a outra congênere ou ao setor público (BRASIL, 2003, p. 69). Ora, como poderiam essas IES deixar de ser comunitárias, confessionais ou filantrópicas para se tornar entidades com fins lucrativos através do Prouni, instituído por medida legal infraconstitucional? Tal situação apenas legitima a transferência pura e simples de patrimônio acumulado por anos de imunidade tributária para a iniciativa privada.

A adesão da Universidade Estácio de Sá ao Prouni é um exemplo disso: maior IES privada do País (mais de 100 mil alunos), mudou seu estatuto de filantrópica para entidade com fins lucrativos. Com isso, passou a pagar a cota patronal do INSS (Instituto Nacional do Seguro Social) e o ISS (Imposto sobre Serviços), mas passou a se beneficiar das isenções do Programa (FOLHA ONLINE, 2004c). Com a mudança, ela não precisa mais oferecer os $20 \%$ de gratuidade $(10 \%$ em bolsas integrais mais $10 \%$ em bolsas parciais e assistência social), mas apenas 10\% (5\% em bolsas integrais e 5\% em parciais). Tal mudança foi lucrativa - não teve de pagar retroativamente nenhum 
tributo e usufruirá o benefício de pagar $100 \%$ da cota patronal apenas dentro de 5 anos.

Enquanto o governo cedia às IES e era elogiado por parte da Anup e da Abruc (Associação Brasileira de Universidades Comunitárias), o MEC restringia-se a "esclarecer dúvidas sobre a Medida Provisória" e a "discutir o que pode vir a ser um sistema de controle do programa” com o Movimento dos Sem Universidade - MSU (FSP, 2004a).

A fiscalização só se efetuará no momento em que o Sinaes estiver totalmente implementado, o que o MEC prevê para 2008. Antes disso, "uma das idéias é realizar convênios entre o ministério e as universidades federais e estaduais, para que elas possam verificar as condiçōes das instituiçôes privadas e enviar essas informaçôes para análise do MEC" (FOLHA ONLINE, 2004b). Entretanto, qual será a força desses convênios de punir efetivamente as IES privadas? Quais providências o MEC tomará diante de pareceres desfavoráveis às IES privadas de má qualidade? Ademais, mesmo que o Sinaes esteja totalmente implantado em 2008, apenas a partir de 2011 alguma instituição vinculada ao Prouni poderá ser punida por sua eventual má qualidade de ensino - e isso se receber três avaliações insuficientes consecutivas na avaliação. Até lá, muitos beneficiários do programa já terão terminado seus cursos superiores.

O PL do Prouni também "flexibilizava" uma das obrigações para que as instituições não-beneficentes e beneficentes usufruíssem, respectivamente, de isenção e imunidade fiscal: o parágrafo único do art. 12 determinava que as IES vinculadas ao Prouni não mais se enquadrariam na exigência da Lei 9.532/97 de "não remunerar, por qualquer forma, seus dirigentes pelos serviços prestados" (BRASIL, PRESIDÊNCIA DA REPÚBLICA, art. $12, \$ 2^{\circ}$, alínea “"). Tal dispositivo foi eliminado posteriormente, uma das poucas derrotas do lobby das mantenedoras.

No início de outubro, a publicação da Instrução Normativa 456 (Secretaria da Receita Federal) determinou regras para as IES que se vinculassem ao Prouni prestarem contas da isenção ao governo. Segundo o art. $4^{\circ}$ da IN, a IES que cometesse "crimes contra a ordem tributária" e que não comprovasse "regular quitação" de suas contribuições e impostos não poderia participar do Programa (BRASIL, SRF, 2004). Embora não fosse nenhuma extravagância, o dispositivo provocou veementes protestos das mantenedoras.

Após tantas alterações e com a pressão por mais privilégios às IES, o governo fechou os números do Prouni para 2005: das 1.652 IES privadas e beneficentes existentes no País, 1.142 IES tiveram sua adesão ao Programa aceitas. Foram 112.416 benefícios oferecidos (72.016 deles integrais) aos candidatos.

\section{A MP NO PARLAMENTO: MAIS UMA OFENSIVA DAS MANTENEDORAS}

Apesar de já ter cedido em diversos pontos ao lobby das mantenedoras, a MP do Prouni sofreu mais mudanças em relação à sua redação original para ser aprovada em primeira votação na Câmara dos Deputados (01.12.2004). A mais relevante decorreu de emenda do deputado oposicionista Paulo Magalhães (PFL-BA), segundo a qual as IES não beneficentes (com ou sem fins lucrativos) destinariam apenas 7,14\% (a redação referia-se a uma bolsa integral para cada 13 alunos pagantes) de suas vagas para aos beneficiários (a MP estabelecia 10\%). Em relação às IES com fins lucrativos, a exigência de ofertar 
bolsas integrais caíra para a proporção de apenas um beneficiário para cada 28 alunos pagantes $(3,44 \%)$. Apenas os $20 \%$ de gratuidade (metade em bolsas integrais e o restante em meias-bolsas e assistência social) das beneficentes foi mantida.

A redução da proporção de bolsistas de $10 \%$ para $7 \%$ foi uma grande derrota do governo. Pouco depois, os senadores aprovaram a MP do Prouni (16.12.2004). A negociação governo-oposição, conduzida pelo líder governista no Senado, Aloízio Mercadante (PT$\mathrm{SP})$, levou a um acordo que deixou o percentual de alunos bolsistas nem nos $7 \%$ da Câmara nem nos $10 \%$ da MP, mas sim em uma média: $8,54 \%$ a partir de 2006 . O comentário do MEC foi o seguinte: "Embora lamente a perda de algumas vagas, o saldo é altamente positivo para a população de baixa renda" (CONSTANTINO, 2004). Não seria bem mais positivo para as mantenedoras?

Seis dias depois, a MP do Prouni, modificada pelo Senado, retornou à Câmara para votação final. Ocorreu, então, uma das poucas derrotas das IES privadas, pois o deputado Colombo, relator do Programa na Câmara, rejeitou a Emenda "que retirava do texto a exigência de as instituições participantes comprovarem a quitação de tributos federais, sob pena de desvinculação do programa" (FOLHA ONLINE, 2004d).

Quanto à seleção, o critério inicial para cadastrar os beneficiários no Prouni continuou sendo a nota de aprovação (fixada em 45 pontos) e a condição socioeconômica declarada no Enem. Considerando que esse exame foi feito por 712 mil de 1,048 milhão de estudantes egressos do ensino médio público, mais de 300 mil foram automaticamente excluídos de se candidatar às bolsas para 2005.

$\mathrm{Na}$ primeira fase de inscrições (encerrada em 20.12.2004), só foram aceitos estudantes que fizeram o Enem em 2004. Até essa data, o Prouni selecionara apenas $64.982^{4}$ (26,62\%) dos 244.088 inscritos (FSP, 2004b). Na segunda fase de inscrições (encerrada em 05.01.2005), foram aceitos estudantes que fizeram o Enem em 2002 e 2003. O MEC contabilizou 154.944 candidatos para as 47.434 bolsas remanescentes (23.321 integrais e 24.113 parciais de $50 \%$ do valor do curso) em 1.135 IES.

Para lidar com a dificuldade de preencher as vagas (em especial bolsas parciais destinadas às cotas para negros e indígenas ${ }^{5}$ ), o MEC estabeleceu que os estudantes com meia-bolsa teriam mais $25 \%$ do valor do curso financiados pelo Fies (RIBEIRO, 2005). Assim, realizou-se uma terceira fase (encerrada em 19.01.2005, com 136.802 inscrições), para as 10.134 bolsas parciais e 6.441 integrais restantes - num total de 16.575 benefícios, 12.786 dos quais prioritários para as cotas raciais. Mesmo assim, houve um excedente de 4.939 vagas, que serão ainda redistribuídas (CONSTANTINO, 2005).

Conforme se salientou, o problema maior do Prouni consiste em enfocar apenas o acesso à educação superior - muitas vezes de qualidade questionável -, e não a permanência do estudante até a conclusão do curso. Nesse sentido, o Observatório Universitário da Universidade Cândido Mendes apresentou pesquisa sobre as dificuldades dos estudantes de baixa renda: "mesmo com os benefícios concedidos pelo Prouni [...], um terço dos estudantes que formam o principal público-alvo do programa terão dificuldade de se manter no ensino superior" (GOIS, 2004a).

A pesquisa constata que $35 \%$ dos estudantes que estão no último ano do ensino médio ou que já o concluíram (3,7 milhōes em um total de 10,5 milhōes): 
...vêm de famílias em que a renda média nem sequer é suficiente para comprar eletrodomésticos de primeira necessidade, como geladeiras, ou que comprometem mais de $40 \%$ do orçamento familiar com aluguel.

...uma família com renda total entre R $\$ 1.000$ e R $\$ 1.200$ consome $82 \%$ de seus recursos com despesas essenciais como alimentação, habitação, transporte, higiene, saúde e vestuário. Em famílias no extremo mais pobre (renda mensal inferior a $\mathrm{R} \$ 400$ ), o orçamento familiar é insuficiente para cobrir essas despesas básicas (GOIS, 2004a).

Uma resposta a problemas dessa natureza poderia estar no projeto do MEC de conceder bolsas-permanência a esses estudantes. Em matéria de 31.08.2004 da Folha de São Paulo, o Ministro Tarso Genro disse que encaminharia proposta de MP para estabelecer loteria federal destinada a "programas de assistência estudantil" que contemplassem "de 60 mil a 80 mil bolsas-permanência - bolsa de um salário mínimo destinada a estudantes de baixa renda" (STACHUK, 2004). Mas em dezembro, quando as bolsas-permanência seriam implementadas (conforme a promessa do Ministro), o próprio Secretário de Educação Superior do MEC não se "lembrou" do Programa: "a secretaria está discutindo com as instituiçõos privadas maneiras de assegurar a permanência desses alunos, mas [...] essa iniciativa deve partir também das universidades" (GOIS, 2004b).

Em suma, um fator essencial da política de educação superior - as condiçôes de permanência no curso para os estudantes de baixa renda - foi simplesmente delegado à iniciativa privada. A proposta da bolsa-permanência seria incluída no texto da Reforma Universitária, mas o MEC ainda não sabia se destinaria tais benefícios a estudantes vinculados ao Prouni. Na melhor das hipóteses, esse é um sinal da falta de articulação na política de educação superior do governo. Também é preciso salientar que o financiamento proposto para essa modalidade de assistência estudantil ainda segue os moldes de financiamento público herdados do Império: as loterias.

\section{LULA SANCIONA A LEI DO PROUNI}

Após tantas alterações ocorridas no Congresso, a Lei do Prouni (n. 11.096/2005) foi finalmente sancionada pelo Presidente da República em 13.01.2005. Embora tenha se cogitado, nos debates do Parlamento, considerar estudantes que tinham cursado apenas parte do ensino médio em escolas públicas como possíveis bolsistas, tal ponto não foi incorporado ao texto final da Lei.

Em seu art. $1^{\circ}$, são mencionados, além de bolsas integral e parcial de $50 \%$, benefícios parciais de $25 \%$ do valor do curso, destinados ao mesmo perfil dos bolsistas de $50 \%$. Meses antes, as IES reivindicavam bolsas parciais de um terço (ou até $20 \%$ ).

A proporção de bolsas integrais nas IES não-beneficentes respeitou o acordo do Senado: para 2005 foi mantido o texto da MP (um benefício para cada nove pagantes), com o acréscimo da possibilidade de desdobramento em bolsas parciais de $25 \%$. Mas de 2006 em diante o percentual foi reduzido a “...1 (uma) bolsa integral para o equivalente a 10,7 (dez inteiros e sete décimos) estudantes regularmente pagantes e devidamente 
matriculados ao final do correspondente período letivo anterior" (art. $\left.5^{\circ}, c a p u t\right)$. Na verdade, essa porcentagem corresponde a $8,54 \%$. No entanto, o $\$ 4^{\circ}$ do mesmo art. $5^{\circ}$ registra " $8,5 \%$ " (ao invés da repetição do texto citado), demonstrando, no mínimo, descuido na redação.

Para tentar "recuperar" minimamente os $10 \%$ de bolsas (reduzidos a $8,5 \%$ no Congresso), inseriu-se punição extra às IES que descumprirem os termos de adesão. $\mathrm{O}$ inciso I do art. $9^{\circ}$ determina que, se a IES não oferecer no mínimo o correspondente a $8,54 \%$ de bolsas integrais, terá que restabelecer esse percentual e acrescentar a ele mais 1/5. Em outros termos, se as IES se comportarem, manterão os $8,5 \%$ conseguidos através do lobby do setor no Parlamento; caso contrário, ficarão sujeitas a 10,24\%.

A MP estabelecia que as IES não beneficentes poderiam oferecer um mínimo de 5\% de bolsas integrais e converter as 5\% restantes em meias-bolsas. Para 2005, a Lei do Prouni manteve essa regra. A partir de 2006, prevê mecanismo parecido, segundo o qual deve haver um mínimo de apenas um bolsista integral para cada 22 alunos pagantes (4,34\%). Os 4,16\% restantes poderão ser "fragmentados" em bolsas parciais de $50 \%$ e $25 \%\left(\operatorname{art} 5^{\circ}, \$ 4^{\circ}\right)$. O efeito estatístico dessa redação é claro: a proporção continuaria em $8,5 \%$, mas a quantidade de beneficiários aumentará significativamente. Entretanto, se considerarmos a faixa de renda familiar per capita (até 3 salários mínimos), a probabilidade de evasão dos bolsistas parciais aumenta ainda mais com benefícios de $25 \%$.

Em relação às IES beneficentes, introduziram-se quatro parágrafos que estabelecem as relações entre o Prouni e o Conselho Nacional de Assistência Social (Cnas), órgão que concede o Certificado de Entidade Beneficente de Assistência Social. Destacamos o art. $11, \$ 2^{\circ}$ : a adesão às regras do Prouni abre a possibilidade deas IES beneficentes em situação ilegal nos dois últimos triênios se regularizarem (obtendo novo certificado) e requererem ao Cnas e ao Ministério da Previdência a reativação da imunidade tributária ( $18 \%$ sobre o lucro líquido e $2 \%$ sobre a receita bruta) perdida.

Há, ainda, outra concessão às IES no texto final da Lei do Prouni: trabalhadores (e seus dependentes) da instituição com renda familiar per capita de até três salários mínimos podem ser contabilizados como beneficiários, "até o limite de 10\% (dez por cento) das bolsas Prouni concedidas" (BRASIL, PODER LEGISLATIVO, 2005, art. 12). Com isso, as IES passaram a dispor de mais um mecanismo para reduzir o percentual de bolsistas novos, reaproximando-o da cifra de 7,5\% defendida pelo Semesp desde setembro de 2004.

Uma das raras derrotas das mantenedoras foi a manutenção do art. 15 da Lei, que obriga as IES a fazer consulta prévia ao Cadastro Informativo de Créditos Não Quitados do Setor Público Federal (Cadin) para garantir as isençôes fiscais do Programa. Outra delas foi o único veto do Presidente da República, referente ao art. 17. O caput do artigo exigia certidão negativa de tributos apenas "ao final do exercício", permitindo, assim, que somente a partir do fim do ano fiscal de 2006 (isto é, fevereiro de 2007) as IES precisassem comprovar não ter dívidas com a Receita (BRASIL, PRESIDÊNCIA DA REPÚBLICA, 2005). Já no parágrafo único do art. 17, o texto não especificava que a isenção seria decorrente das receitas auferidas com atividades de ensino superior das mantenedoras. Portanto, estas poderiam presumir que, ao se vincular ao Prouni, gozariam de isenção tributária inclusive para atividades que não as de ensino superior. 
Por fim, há dois aspectos que causam estranhamento na Lei do Prouni. O primeiro é o art. 18 ("O Poder Executivo dará, anualmente, ampla publicidade dos resultados do programa"), talvez elaborado com o intuito de não incluir as despesas de publicidade do Programa nas verbas públicas destinadas à propaganda governamental. $\mathrm{O}$ segundo é a inclusão de dois artigos destinados a alterar a Lei 10.891/2004 (que instituiu a BolsaAtleta), que não apresenta vínculo algum com o Prouni.

\section{CONSIDERAÇÕES FINAIS}

O comentário do presidente da Abmes não deixa dúvida em relação aos princípios orientadores do Prouni: "A proposta não saiu como pretendíamos, mas é razoável e favorece as instituições privadas" (MENA, 2004). O Programa parece tentar aliar cidadania e privatização. Acaba fortalecendo ainda mais as IES privadas - pois expande o segmento através do aumento do número de matrículas (ao invés de fazê-lo prioritariamente no setor público, conforme determinava o PNE) - e alimenta a mercantilização da educação superior.

Como destacam Ivan Valente e Otaviano Helene, "o que o Prouni faz é aumentar as isenções fiscais para IES privadas, que, com poucas exceções, não prestam contas de como as usam, remuneram de forma ilegal seus sócios, não têm transparência na concessão de bolsas e maquiam balanços" (VALENTE; HELENE, 2004). Conforme os autores ressaltam, os privilégios concedidos às IES privadas poderiam ser direcionados ao gasto no setor público.

No entanto, para cumprir a meta do PNE de ampliar de $9 \%$ para $30 \%$ a população jovem de 18 a 24 anos no ensino superior até 2010 (reivindicação das mantenedoras voltada à ampliação de seu mercado), o MEC optou por uma política pública voltada à concessão de benefícios e não à promoção de direitos, enfocando quase que exclusivamente o acesso - e não a permanência - do estudante ao nível superior. Quanto à alegação do governo (ver HADDAD e BACHUR, 2004) de que a concessão de bolsas em IES privadas e filantrópicas é complementar - e não antagônica - à universidade pública, cabe lembrar que o Programa "...contribui para o aumento da oferta privada nesse campo. Assim, o que está em jogo não é o 'afastamento' da ação estatal, senão sua reconfiguração quanto à oferta do ensino superior” (MANCEBO, 2004, p. 85).

Nesse sentido, mesmo como mera política assistencialista, o Prouni mostra fraquezas, porque espera que as IES privadas "cuidem" da permanência do estudante. Tal postura não se distancia da metáfora da Lei Áurea mencionada na epígrafe: quebram-se algumas correntes que impediam o acesso à educação superior, mas não se oferece mais do que um arremedo de cidadania de segunda classe aos contemplados. Além da qualidade questionável dos cursos oferecidos, os beneficiários terão acesso a um ensino privatista e pautado pela falta de condições que garantam sua permanência até a obtenção do diploma. 


\section{Notas}

1. Estes só poderiam escolher cursos de licenciatura ou pedagogia voltados à educação básica (o "normal superior" foi incluído na Lei $\left.\mathrm{n}^{\circ} 11.096 / 2005\right)$.

2. O MEC irá regulamentar posteriormente quem será considerado aluno regularmente pagante a partir de 2006; para 2005 valem os termos de adesão assinados entre as IES e o MEC.

3. Para piorar o quadro, a Abmes sugere a revogação do art. $5^{\circ}$ da Lei 9.870/99 e propõe que as mensalidades escolares sejam regidas pelo "mesmo princípio adotado nos contratos de prestação de serviços médicos, nos planos de saúde (após o terceiro mês de inadimplência o contratante é desligado do sistema)" (CARBONARI NETTO, 2004, p. 11-12).

4. Nesse total, havia 596 professores, 759 estudantes com necessidades especiais, 2.984 bolsistas integrais durante os três anos do ensino médio privado e 20.967 autodeclarados negros ou indígenas (FOLHA ONLINE, 2004e).

5. Estas tiveram baixa procura no segmento, cuja renda familiar muitas vezes não permite sequer arcar com $50 \%$ ou $25 \%$ das mensalidades de IES privadas.

\section{Referências}

BRASIL. Constituição da República Federativa do Brasil. Constituição do Estado de São Paulo. Declaração Universal dos Direitos Humanos. São Paulo: Imprensa Oficial do Estado de São Paulo, 2003.

BRASIL, MEC. Projeto de Lei n. 3.582, de 28.04.2004. Dispõe sobre a instituição do Programa Universidade para Todos - Prouni, e dá outras providências. Brasília: MEC, 2004 (http://www.camara.gov.br/sileg/integras/219649.htm, consulta: 06.01.05).

BRASIL, PODER EXECUTIVO. Medida Provisória n. 213, de 10.09.2004. Institui o Programa Universidade para Todos - Prouni, regula a atuação de entidades beneficentes de assistência social no ensino superior, e dá outras providências, DOU, 13.10.2004 (http://www.presidencia.gov.br/ccivil/_ato2004-2006/2004/mpv/213.htm, consulta: 07.01 .05$)$.

Lei no 11.096, de 13.01.2005. Institui o Programa Universidade para Todos - Prouni, regula a atuação de entidades beneficentes de assistência social no ensino superior, altera a Lei n. 10.981, de 9 de julho de 2004, e dá outras providências, DOU, 14.01.2005 (http://www.in.gov.br, consulta: 14.01.05).

BRASIL, PRESIDÊNCIA DA REPÚBLICA. Lei n. 9.532, de 10.12.1997. Altera a legislação tributária e dá outras providências, DOU, 11.12.1997 (http://www.advocaciasantos.com.br/lei_9532_97.htm, consulta: 07.01.05)

Lei n. 9.870, de 23.11.1999. Dispõe sobre o valor total das anuidades escolares e dá outras providências, DOU, 24.11.1999 (http://planalto.gov.br/ccivil_03/Leis/L9870.htm, consulta: 07.01.05).

. Mensagem n. 14, de 13.01.2005, DOU, 14.01.2005 (http://www.in.gov.br, consulta: 14.01.05).

BRASIL, SECRETARIA DA RECEITA FEDERAL (SRF). Instrução Normativa n. 456, de 05.10.2004. Dispõe sobre a isenção do imposto de renda e de contribuiçôes aplicável às instituiçóes que aderirem ao Programa Universidade para Todos, DOU, 08.10.2004 (http://prouni.mec.gov.br/prouni/inst_normativa.asp, consulta: 04.01.2005).

CARBONARI NETTO, Antonio (Coord.); COVAC, José Roberto et al. A reforma da educação superior. princípios e diretrizes. Brasília: Abmes, [13.08.]2004 (http://www.abmes.org.br/Textos/Manuais/Reforma _Universitaria/propostas_principios.doc, consulta: 07.01.05).

COLLUCCI, Cláudia. Um terço dos alunos não pode se inscrever no Prouni. Folha de São Paulo, São Paulo, 31.12.2004 (http://www1.folha.uol.com.br/folha/educacao/ult305u16797.shtml, consulta: 31.12.04).

CONSTANTINO, Luciana. Programa de bolsas nas universidades é aprovado no Senado. Folha de São Paulo, São Paulo, 17.12.2004 (http://www1.folha.uol.com.br/folha/educacao/ult305u16740.shtml, consulta: 05.01.05).

. MEC reforça auxílio a bolsistas carentes. Folha de São Paulo, "Cotidiano", 26.01.2005, p. C5. 
FOLHA DE S. PAULO (FSP). MEC quer criar controle do Prouni. FSP, São Paulo, 21.09.2004, $2004 a$. $2004 \mathrm{~b}$. Programa de bolsa do governo federal seleciona 26,62\% dos candidatos. FSP, São Paulo, 21.12.2004,

Lula sanciona lei do Prouni e defende cotas. FSP, “Cotidiano", São Paulo, 14.01.2005.

FOLHA ONLINE. Universidades particulares pedem alteração em reserva de vagas. Folha Online, "Educação", 12.08.2004, 2004a (http://wwwl.folha.uol.com.br/folha/educacao/ult305u15930.shtml, consulta: 05.01.05).

MEC vai fiscalizar universidades participantes do Prouni. Folha Online, "Educação", 23.09.2004, $2004 \mathrm{~b}$ (http://www1.folha.uol.com.br/folha/educacao/ult305u16099.shtml, consulta: 05.01.05).

. Estácio anuncia adesão ao Prouni e deixa de ser filantrópica. Folha Online, "Educação", 01.10.2004, 2004c (http://www1.folha.uol.com.br/folha/educacao/ult305u16160.shtml, consulta: 05.01.05).

Câmara aprova MPs do Prouni e do Biodiesel. Folha Online, "Brasil", 22.12.2004, 2004d (http://www1.folha.uol.com.br/folha/brasil/ult96u66392.shtml, consulta: 05.01.05).

Inscriçōes ao Prouni terminam nesta sexta-feira. Folha Online, "Educação", 29.12.2004, 2004e (http://www1.folha.uol.com.br/folha/educacao/ult305u16780.shtml, consulta: 05.01.05).

GOIS, Antônio. Estudo indica que bolsa não garante aluno na faculdade. FSP, São Paulo, 27.12.2004, 2004a (http://www1.folha.uol.com.br/folha/educacao/ult305u16766.shtml, consulta: 05.01.05).

"Quase desisti", afirma estudante carente do Rio. FSP, "Cotidiano", São Paulo, 27.12.2004, 2004b (http://www1.folha.uol.com.br/folha/educacao/ult305u16767.shtml, consulta: 29.12.04).

HADDAD, Fernando; BACHUR, João Paulo. Um passo atrás, dois à frente. FSP, “Tendências/Debates", São Paulo, 11.12.2004 (http://www1.folha.uol.com.br/fsp/opiniao/fz1112200409.htm, consulta: 05.01.05).

MANCEBO, Deise. "Universidade para todos": a privatização em questão. Pro-Posiçôes, v. 15, n. 3 (45), p. 75 90, set./dez. 2004.

MENA, Fernanda. Pareceres da FGV e de consultoria divergem sobre número de vagas. FSP, São Paulo, 17.12.2004 (http://www1.folha.uol.com.br/folha/educacao/ult305u16741.shtml, consulta: 05.01.05).

O ESTADO DE S. PAULO (OESP). Particulares reagem com mudanças no Prouni. OESP, 27.05.2004 (http://www.estadao.com.br/educando/noticias/2004/mai/27/103.htm, consulta: 06.01.05).

PARAGUASSÚ, Lisandra. Projeto do Prouni recebe 292 emendas. O Estado de S. Paulo, São Paulo, 05.06.2004 (http://www.estadao.com.br/educando/noticias/2004/jun/05/68.htm, consulta: 06.01.05).

RIBEIRO, Ana Paula. MEC reabre inscriçōes no Prouni a partir do dia 12 de janeiro. Folha Online, 07.01.2005 (http://www1.folha.uol.com.br/folha/educacao/ult305u16851.shtml, consulta: 08.01.05).

SEMESP. Seminário (23.09.2004). São Paulo, Semesp, 2004 (http://www.semesp.org.br/seminario230904.htm, consulta: 10.01 .05$)$.

SILVA JÚNIOR, João dos Reis; CATANI, Afrânio Mendes. Com a bola quadrada. Reportagem - Revista da Oficina de Informações, v. 5, n. 56, p. 43-45, maio 2004.

STACHUK, Mayra. MP criará loteria para ajudar aluno no ensino superior. FSP, São Paulo, 31.08.2004 (http://www1.folha.uol.com.br/folha/educacao/ult305u16007.shtml, consulta: 05.01.05).

TAKAHASHI, Fábio. Prouni pode ter meia bolsa e vestibular a beneficiados. Folha Online, 01.07.2004 (http://www1.folha.uol.com.br/folha/educacao/ult305u15709.shtml, consulta: 05.01.05).

VALENTE, Ivan; HELENE, Otaviano. O Prouni e os muitos enganos. FSP, "Tendências/Debates", São Paulo, 11.12.2004 (http://wwwl.folha.uol.com.br/fsp/opiniao/fz1112200410.htm, consulta: 05.01.05). 


\section{Prouni at a crossroad: between citizenship and privatization}

Abstract

This paper intends to discuss the relationship between the Brazilian government and representatives of supporting institutions of Higher Education in the process of writing, changing and approving the Program University For All (Prouni), ione of the components of Higher Education Reform of the Lula government. The incorporated modifications represent, above all, concessions to the lobby of private institutions of Higher Education, which was victorious in almost all of its demands. In this context, Prouni can be considered as promoting access to - but not permanence in - higher education for low-income students. The Program offers a second-class citizenship to the students, leaves them in the hands of the private enterprise, broadens the power of the private sector institutions, and saves the privatelyowned higher educational institutions from the chronical problem of student evasion.

Keywords: Higher education. Access. Permanency. Prouni.

\section{Prouni au croisement : entre la citoyenneté et la privatisation}

Résumé

L'objectif de cet article est de discuter la relation entre le gouvernement et les associations des organisations d'enseignement supérieur dans le processus d'élaboration, modification et approbation du Programme Université pour Tous (Prouni) qui intègre la Réforme Universitaire du gouvernement Lula. Les changements incorporés représentent surtout, des concessions au lobby des instituitions d'enseignement supérieur du secteur privé, qui a obtenu presque toutes ses revendications. Dans ce contexte, le Prouni peut être charactérisé comme dirigé à promouvoir l'accès, et non la permanence, d'étudiants de bas niveau économique à l'enseignement supérieur. Le programme offre une citoyenneté de seconde catégorie aux bénéficiés, et les abandonne à l'initiative privée, élargit le pouvoir des institutions d'enseignement supérieur du secteur privé et les sauve du problème chronique de l'évasion d'étudiants.

Mots clefs : Éducation supérieure. Accès. Permanence. Prouni.

\section{EI Prouni en la encrucijada: entre la cidadania y la privatización}

\section{Resumen}

El objetivo del articulo es discutir la relación entre gobierno y asociaciones de las mantenedoras de enseñanza superior en el proceso de elaboración, modificación e aprobación del programa Universidad para Todos (Prouni), que integra la reforma universitaria del gobierno Lula. Las alteraciones incorporadas representan, sobretudo, concesiones al lobby de las instituciones de enseñanza superior (IES) del sector privado, que obtuvo casi todas sus reivindicaciones. En ese contexto, el Prouni puede ser caracterizado como destinado a promover el acceso - y no la permanencia - de estudiantes de baja renta al nivel superior. El programa ofrece una ciudadania de segunda clase a los becados, les abandona a la iniciativa privada, amplia el poder de las IES del sector y las salva del crónico problema dela evasión de alumnos.

Palabras-clave: Educación superior. Acceso. Permanencia. Prouni.

Recebido: 09.02 .2005

Aceito: 13.05 .2005 